\title{
Optimized and Non-Optimized Personal Protective Equipment use During the COVID-19 Pandemic in Thailand: A National Cross-Sectional Survey in a Resource-Limited Setting
}

\section{Visal Moolasart ( $\nabla$ vismool@yahoo.com )}

Bamrasnaradura Infectious Disease Institute https://orcid.org/0000-0002-1151-4790

\section{Weerawat Manosuthi}

Bamrasnaradura Infectious Disease Institute

Varaporn Thienthong

Bamrasnaradura Infectious Disease Institute

\section{Uajai Jaemsak}

Bamrasnaradura Infectious Disease Institute

Pimonamorn Pantool

Bamrasnaradura Infectious Disease Institute

\section{Suthat Chottanapund}

Bamrasnaradura Infectious Disease Institute

\section{Research}

Keywords: Optimized personal protective equipment, COVID-19 pandemic, Knowledge and degree

Posted Date: October 8th, 2020

DOI: https://doi.org/10.21203/rs.3.rs-86150/v1

License: (c) (i) This work is licensed under a Creative Commons Attribution 4.0 International License.

Read Full License

Version of Record: A version of this preprint was published at Environmental Health Insights on January 1st, 2021. See the published version at https://doi.org/10.1177/11786302211013545. 


\section{Abstract}

Background: Coronavirus disease (COVID-19) is caused by the severe acute respiratory syndrome coronavirus 2 (SARS-COV2). COVID-19 is highly contagious, potentially fatal, and a global public health concern. Combining optimized personal protective equipment (PPE) use and hand hygiene is the best strategy for preventing COVID-19 in health care workers (HCWs).

Methods: We conducted a national cross-sectional survey of HCWs in the infection control program in Thailand between May 5, 2020 and May 15, 2020. The primary objective was the prevalence of optimized PPE use amongst HCWs. The secondary objective was identification of the independent predictors of optimized PPE use.

Results: Seven hundred and fifty-six HCWs responded. Five HCWs were excluded because of non responsible of care team, and 751 were included in the final analysis. The prevalence of optimized PPE use was $22 \%$ (168/751), 78\% (583/751) were non-optimized PPE use, 35\% (263/751) over-used PPE, and $43 \%$ (320/751) under-used PPE. In univariate analysis, optimized PPE use was significantly associated with age, education level, knowledge of appropriate negative pressure room selection and knowledge of apparently milder symptom severity in children than adults. In multivariate analysis, independent predictors of optimized PPE use were knowledge of appropriate negative pressure room selection $(\mathrm{aOR}=1.95,95 \% \mathrm{Cl}=1.18-3.22)$, the difference in symptom severity between children and adults $(\mathrm{aOR}=0.55,95 \% \mathrm{Cl}=0.37-0.81)$ and education level $(\mathrm{aOR}=1.54,95 \% \mathrm{Cl}=1.04-2.27)$.

Conclusion: The prevalence of optimized PPE use amongst HCWs was $22 \%$. Independent predictors of optimized PPE use were COVID-19 knowledge-based factors and education level.

Continued education is advised among Thai HCWs.

\section{Introduction}

Coronavirus disease (COVID-19) is caused by the severe acute respiratory syndrome coronavirus 2 (SARSCOV2) and COVID-19 is a potentially fatal disease of great global public health concern [1]. SARS-COV2 is transmitted by respiratory droplets by direct close contact of the exposed mucous membranes including the mouth, nose and possibly the conjunctiva, indirect contact by fomites in the immediate environment of the infected person, and by the fecal-oral route [2-4]. It is thought that airborne transmission is unlikely. The basic reproduction number (R0) is the expected number of cases generated by one case when the entire population is susceptible, and the estimates of the R0 of COVID-19 have varied widely[5,6]. The symptoms of COVID-19 are similar in children and adults but appear to be milder in children [7].

Health care workers (HCWs) are a population at high risk of SARS-COV2 infection. As of 3 April 2020, around $10000 \mathrm{HCWs}$ in Italy were infected, of whom 74 had died, and many other HCWs have formed large clusters of infections with many deaths in countries globally [8-10]. The COVID-19 pandemic has 
led to shortages of personal protective equipment (PPE) for general populations, patients, and especially HCWs because SARS-COV2 can be transmitted even by COVID-19 infected individuals who are not yet showing signs of infection [11,12]. On 7 February 2020, the World Health Organization (WHO) estimated that demand for PPE had increased by 100 -fold, and prices had increased by up to 20 -fold since the start of the outbreak [13]. The several previous studies and national regulatory bodies have recommended gloves, a gown, a surgical mask and goggles/a face shield as optimized PPE for HCWs in close contact with COVID-19 patients [14-17]. At present, the transmission of disease by the conjunctiva is not certain. Animal models demonstrated this mode of transmission, so eye protection should be considered as a part of PPE $[18,19]$.

The WHO recommendations for PPE for HCWs working in patient rooms/wards in the absence of aerosolgenerating procedures are according to the setting, personnel, and type of activity and include medical masks, gown, glove, and eye protection (goggles or face shields) accompanied by hand hygiene. Coveralls, double gloves, or head covers (hoods) that cover the head and neck used in the context of filovirus disease outbreaks (e.g. Ebola virus) are not required when managing COVID-19 patients [20]. Overall, optimized PPE and hand hygiene using alcohol-based hand rub (ABHR) or washing with soap and water can reduce rates of disease transmission and protect HCWs. However, the overuse or misuse of standard PPE have detrimental effects, including supply shortages of hoods, mask types, and limiting the potential re-use of equipment [21-23]. It is equally important that HCWs use it appropriately to preserve what may be limited stocks to ensure there is sufficient supply for necessary use throughout an epidemic surge. For at risk HCWs, there are many strategies for to control COVID-19 during the COVID-19 pandemic, such as social distancing or physical distancing [24] and 14-day quarantine [25]. Although influenza vaccine is not effective against the COVID-19 virus [26], this vaccine is advisable for the public and HCWs to reduce influenza incidence, allowing for more capacity in health care systems to be devoted to manage COVID-19. Disinfectant regimens that are effective against COVID-19 include a hypochlorite-based regimen $(0.1-0.5 \%), 70 \%$ ethyl alcohol, povidone-iodine ( $1 \%$ iodine), chloroxylenol $(0.24 \%), 50 \%$ isopropanol, $0.05 \%$ benzalkonium chloride, $1 \%$ cresol soap, or hydrogen peroxide (0.5-7.0\%) [27]. The disinfectant regimen chosen should be performed 3 times a day and be repeated each time there is contamination [28]. The WHO has stated that spraying individuals with disinfectants is not recommended under any circumstances because of physically and psychologically harmful effects without reducing an infected person's ability to spread the virus through droplets or contact [29].

The Department of Disease Control of Thailand assigned the Bamrasnaradura Infectious Diseases Institute (BIDI) to the infection prevention control program (IPC) and network. BIDI has several programs, such as infection control surveillance and point prevalence survey [30], including the use of PPE in HCWs. To date, optimized PPE use data in HCWs in Thailand has rarely been reported. Therefore, we aimed to estimate the prevalence of HCWs who used optimized PPE and also to identify the independent predictors of optimized PPE use.

\section{Methods}


We conducted a retrospective, national cross-sectional survey of HCWs in the IPC network in Thailand between May 5, 2020 and May 15, 2020. The study protocol was reviewed and approved by Institutional Review Board of BIDI, Ministry of Public Health, Thailand. The reference approval letter number is S042h/63_ExPD. Informed consent was waived as participant data were de-identified. The primary objective was to estimate the prevalence of HCW who used optimized PPE. The secondary objective was identification of the independent predictors of optimized PPE use and non-optimized PPE use. Optimized PPE use was defined as HCWs using PPE including medical masks, gowns, gloves, eye protection (goggles or face shields), performing appropriate hand hygiene as well as not using coveralls, double gloves, or head covers (hoods) [20]. Non-optimized PPE was defined as HCWs using incomplete appropriate PPE or over-using PPE.

We extracted demographic, work experience and setting, knowledge, attitudes and practices data, including established sex, age, education (bachelor degree or postgraduate degree), experience in hospital work (<1 y, 1-5 y, 6-10 y, 11-20 y, and $\geq 20 \mathrm{y}$ ), experience in IPC (<1 y, 1-5 y, 6-10 y, 11-20 y, and $\geq 20$ y), hospital type (primary, secondary, tertiary, university, private, army, and other), care type (adult only, child only, as well as both adult and child), experience with COVID-19 (yes or no), droplet and contact precaution(yes or no), ABHR practice (yes or no), wash with soap and water (yes or no), appropriate disinfectant regimen use (i.e. 70\% ethyl alcohol, sodium hypochlorite-based, or both alcohol and sodium hypochlorite), appropriate negative pressure room selection (negative pressure rooms for all situation or not), selecting N95 respirator for all situations (yes or no), single room (use air conditioning all the time or not), knowledge that symptom severity in children is apparently milder than in adults (yes or no), spraying disinfectant (yes or no), advising influenza vaccine (yes or no), visit strategy (yes or no), discharge plan for patients including social distancing, $\mathrm{HH}$, and mask (yes or no), discharge plan for family including social distancing, $\mathrm{HH}$, and mask (yes or no), advising people to wear masks (yes: advise cloth mask or no), fear of COVID-19 infection (yes: afraid or no), and fear of sickness and 14-day quarantine (yes or no).

The definitions for appropriate hand hygiene, social and physical distancing, as well as 14-day quarantine for items used in the questionnaire survey are listed below. All HCWs should use droplet and contact precautions in routine practice for care of patients with suspected or confirmed COVID-19 [14$17,20]$. For our questionnaire survey, appropriate hand hygiene practice by HCWs was defined as an ABHR that contained at least $60 \%$ alcohol for a minimum of 20 seconds or washing with soap and water at the beginning of the workday, before and after touching residents, after using the toilet, before and after preparing food, and before eating [22,23]. We defined social distancing or physical distancing according to the Centers of Disease Control and Prevention of the United States' definition of maintaining a physical distance of $2 \mathrm{~m}$ or more from other people [24]. We defined appropriate 14-day quarantine as 14-day quarantine of close contacts of a HCW infected with COVID-19 [25]. Influenza vaccination was advised for the public including HCWs during the COVID-19 pandemic [26]. All HCWs should be checked twice a day for ARIS symptoms, and body temperature to increase the chances of early diagnosis. If a member of the team is infected with COVID-19, all close contacts should take quarantine measures [31].

\section{Statistical analysis}


Descriptive statistics are presented as mean (SD) for normally distributed continuous variables, median (Q1, Q3) for non-normally distributed continuous variables, and frequency (\%) for categorical variables. All continuous data were compared with the Student's t-test or the Mann-Whitney U test as appropriate. Categorical data were compared with the chi-square test. A p-value of $<0.05$ was considered statistically significant. Multivariable logistic regression was used to identify independent predictors of optimized PPE use. All variables with p-value $<0.05$ in univariate analyses were selected for multivariate analysis. Factors considered were sex, age, education level, experience in hospital work, experience in IPC work, hospital type, care type, experience in COVID-19, droplet and contact precaution, ABHR practice, hand hygiene by washing with soap and water, disinfectant, knowledge of appropriate negative pressure room selection, selecting N95 respirator in all situations, single room, knowledge of apparently milder symptoms in children than adults, spray disinfectant, advising influenza vaccination, visit strategy, discharge plan for patient, discharge plan for family, advising people to wear mask, fear of COVID-19 infection, and fear of sickness and 14-day quarantine.

\section{Results}

Figure 1 shows a flow chart of the study population. Seven hundred and fifty-six HCWs responded. Five $\mathrm{HCWs}$ were excluded because of non responsible of care team. Therefore, $751 \mathrm{HCWs}$ were included in the final analysis. Of these, the prevalence of optimized PPE use for COVID-19 was 22\% (168/751). Seventyeight percent (583/751) did not use optimized PPE for COVID-19 with 35\% (263/751) of HCWs over-using PPE and $43 \%$ (320/751) of HCWs (43\%) under-using PPE.

Table 1 displays the demographics and characteristics of the HCWs responding to the survey. The majority were female, and the mean age (SD) of those with optimized PPE use and non-optimized PPE use were $46.1(6.5)$ and $44.6(8.2)$ years $(p=0.015)$, respectively. Education level was also significantly different $(p<0.05)$. Sex, number of beds in health care facility, experience in hospital work, experience in IPC work, hospital type, care type, and experience in COVID-19 of both groups were not significantly different $(p<0.05)$. 
Table 1

Demographics and characteristics of health care workers $(\mathrm{N}=751)$

\begin{tabular}{|c|c|c|c|}
\hline Characteristics & $\begin{array}{l}\text { Optimized PPE } \\
\text { use } \\
(n=168)\end{array}$ & $\begin{array}{l}\text { Non- optimized PPE use } \\
(n=583)\end{array}$ & P-value \\
\hline Sex, $n(\%)$ & 166(98.8) & $559(95.9)$ & 0.091 \\
\hline Female & $2(1.2)$ & $24(4.1)$ & \\
\hline \multicolumn{4}{|l|}{ Male } \\
\hline Age, mean(SD), y & $46.1(6.5)$ & $44.6(8.2)$ & $0.015^{\star}$ \\
\hline $\begin{array}{l}\text { No. beds in health care facility, } \\
\text { mean(SD) }\end{array}$ & $220(367)$ & 172(229) & 0.106 \\
\hline Education level, $\mathrm{n}(\%)$ & & & $0.011^{\star}$ \\
\hline Bachelor degree & 114(67.9) & $453(77.7)$ & \\
\hline Postgraduate degree & $54(32.1)$ & $130(22.3)$ & \\
\hline Experience in hospitalized work, $\mathrm{n}(\%)$ & & & 0.080 \\
\hline$<1 \mathrm{y}$ & $1(0.6)$ & $5(0.9)$ & \\
\hline $1-5 y$ & $3(1.8)$ & $24(4.1)$ & \\
\hline $6-10 y$ & $4(2.4)$ & $41(7.0)$ & \\
\hline $11-20 y$ & $46(27.4)$ & $159(27.3)$ & \\
\hline$\geq 20 y$ & 114(67.9) & $354(60.7)$ & \\
\hline Experience in IPC work, $\mathrm{n}(\%)$ & & & 0.382 \\
\hline$<1 \mathrm{y}$ & $9(5.4)$ & $56(9.6)$ & \\
\hline $1-5 y$ & $48(28.6)$ & 156(26.8) & \\
\hline $6-10 y$ & $45(26.8)$ & $134(23.0)$ & \\
\hline $11-20 y$ & $48(28.6)$ & $181(31.0)$ & \\
\hline$\geq 20 y$ & 18(10.7) & $56(9.6)$ & \\
\hline Hospital type, n(\%) & & & 0.788 \\
\hline Primary & $99(58.9)$ & $365(62.6)$ & \\
\hline Secondary & $34(20.2)$ & 115(19.7) & \\
\hline
\end{tabular}

Notes:- *Statistically significant result at the $p<0.05$ level. Abbreviations: COVID-19, coronavirus disease 2019; PPE, personal protective equipment; IPC, infection control program 


\begin{tabular}{|c|c|c|c|}
\hline Characteristics & $\begin{array}{l}\text { Optimized PPE } \\
\text { use } \\
(n=168)\end{array}$ & $\begin{array}{l}\text { Non- optimized PPE use } \\
(n=583)\end{array}$ & $P$-value \\
\hline Tertiary & $21(12.5)$ & $55(9.4)$ & \\
\hline University & $3(1.8)$ & $11(1.9)$ & \\
\hline Private & $8(4.8)$ & $31(5.3)$ & \\
\hline Army & $2(1.2)$ & $3(0.5)$ & \\
\hline Other & $1(0.6)$ & $3(0.5)$ & \\
\hline Care type, n(\%) & & & 0.781 \\
\hline Adult only & $20(11.9)$ & $80(13.7)$ & \\
\hline Child only & $2(1.2)$ & $11(1.9)$ & \\
\hline Dual adult and child & $146(86.9)$ & $492(84.4)$ & \\
\hline Experience in COVID-19, n(\%) & & & 0.052 \\
\hline Yes & $83(49.4)$ & $238(40.8)$ & \\
\hline No & $85(50.6)$ & $345(59.2)$ & \\
\hline
\end{tabular}

Table 2 displays the knowledge, attitudes and practices of HCW towards COVID-19 comparing those with optimized PPE use and those without optimized PPE use. Knowledge about appropriate negative pressure room selection and the fact that COVID-19 symptoms appear to be milder in children than in adults were significantly different $(p<0.05)$. Droplet and contact precaution, ABHR practice, hand hygiene by washing with soap and water, disinfectant, selection of N95 respirator for all situations, single room, spraying disinfectant, advising about influenza vaccine, visit strategy, discharge plan for patient, discharge plan for family, advising people to wear a mask, fear of COVID-19 infection, fear of sickness and 14-day quarantine were not significantly different $(p<0.05)$. 
Table 2

Practices, knowledge and attitudes of HCW towards COVID-19 ( $\mathrm{N}=751)$

\section{Characteristic}

\section{Optimized} PPE use

$(n=168)$
Non- optimized

PPE use

$(n=583)$

\section{Practices}

Droplet and contact precaution

Yes

162(96.4)

571(97.9)

No

$6(3.6)$

12(2.1)

ABHR practice

Yes

161(95.8)

$561(96.2)$

No

$7(4.2)$

22(3.8)

Washing with soap and water

0.738

Yes

160(95.2)

$551(94.5)$

No

$8(4.8)$

$32(5.5)$

Disinfectant

23(13.7)

$90(15.4)$

Using 70\% ethyl alcohol

$5(3.0)$

$31(5.3)$

Using sodium hypochlorite-based

140(83.3)

$462(79.2)$

Using both alcohol and sodium hypochlorite-based

Knowledge

Negative pressure room

$0.004^{\star}$

Appropriate negative pressure room selection

21(12.5)

$130(22.3)$

No

147(87.5)

453(77.7)

Selecting N95 respirator for every situation

Yes

$5(3.0)$

29(5.0)

No

163(97.0)

$554(95.0)$

Single room

0.335

Using air conditioning all the time

$17(10.1)$

$44(7.5)$

No

151(89.9)

$539(92.5)$

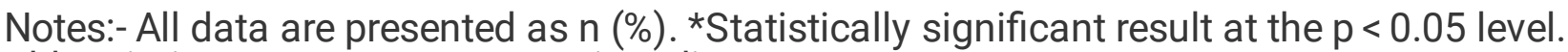

Abbreviations: COVID-19, coronavirus disease 2019; 


\begin{tabular}{|c|c|c|c|}
\hline Characteristic & $\begin{array}{l}\text { Optimized } \\
\text { PPE use } \\
(n=168)\end{array}$ & $\begin{array}{l}\text { Non- optimized } \\
\text { PPE use } \\
(n=583)\end{array}$ & $\begin{array}{l}P- \\
\text { value }\end{array}$ \\
\hline $\begin{array}{l}\text { COVID-19 symptoms appear to be milder in } \\
\text { children than in adults }\end{array}$ & & & $0.001 *$ \\
\hline Yes & $127(75.6)$ & $361(61.9)$ & \\
\hline No & $41(24.4)$ & $222(38.1)$ & \\
\hline Spraying disinfectant & & & 0.427 \\
\hline Yes & $3(1.8)$ & $6(1.0)$ & \\
\hline No & 165(98.2) & $577(99.0)$ & \\
\hline Advising influenza vaccine & & & 0.076 \\
\hline Yes: advising & $16(9.5)$ & $88(15.1)$ & \\
\hline No & 152(90.5) & $495(84.9)$ & \\
\hline Visit strategy & & & 0.555 \\
\hline No & $126(75.0)$ & $422(72.4)$ & \\
\hline Yes, stop go to room & $42(25.0)$ & $161(27.6)$ & \\
\hline $\begin{array}{l}\text { Discharge plan for patient } \\
\text { (distancing/HH/mask) }\end{array}$ & & & 1.000 \\
\hline Yes & 163(97.0) & $566(97.1)$ & \\
\hline No & $5(3.0)$ & $17(2.9)$ & \\
\hline $\begin{array}{l}\text { Discharge plan for family } \\
\text { (distancing/HH/mask) }\end{array}$ & & & 0.063 \\
\hline Yes & $86(51.2)$ & $347(59.5)$ & \\
\hline No & $82(48.8)$ & $236(40.5)$ & \\
\hline Advise people mask & & & 0.444 \\
\hline Advising to wear cloth mask & 165(98.2) & $563(96.6)$ & \\
\hline Not advising to wear cloth mask & $3(1.8)$ & $20(3.4)$ & \\
\hline
\end{tabular}

Notes:- All data are presented as $n(\%)$. *Statistically significant result at the $p<0.05$ level. Abbreviations: COVID-19, coronavirus disease 2019; 


\begin{tabular}{|llll|}
\hline Characteristic & $\begin{array}{l}\text { Optimized } \\
\text { PPE use } \\
(\mathbf{n}=168)\end{array}$ & $\begin{array}{l}\text { Non- optimized } \\
\text { PPE use } \\
(\mathbf{n}=583)\end{array}$ & $\begin{array}{l}\text { P- } \\
\text { value }\end{array}$ \\
\hline Fear of COVID-19 infection & & & 0.315 \\
\hline Yes, afraid & $132(78.6)$ & $478(82.0)$ & \\
\hline No & $36(21.4)$ & $105(18.0)$ & \\
\hline Fear of sick and 14-day quarantine & & & \\
\hline Yes, afraid & $128(76.2)$ & $451(77.4)$ & \\
\hline No & $40(23.8)$ & $132(22.6)$ & \\
\hline $\begin{array}{l}\text { Notes:- All data are presented as } n \text { (\%). *Statistically significant result at the } \mathrm{p}<0.05 \text { level. } \\
\text { Abbreviations: COVID-19, coronavirus disease 2019; }\end{array}$ & & \\
\hline
\end{tabular}

Table 3 displays factors associated with optimized PPE use. In multivariate analysis, independent predictors of optimized PPE were knowledge about the appropriate negative pressure room selection for COVID-19 (aOR $=1.95,95 \% \mathrm{Cl}=1.18-3.22)$, knowledge of apparently milder symptom severity in children compared to adults $(\mathrm{aOR}=0.55,95 \% \mathrm{Cl}=0.37-0.81)$, and education level: postgraduate degree $(\mathrm{OR}=$ $1.54,95 \% \mathrm{Cl}=1.04-2.27)$.

Table 3

Associations of optimized PPE use in HCW by multivariable multinomial logistic regression

\begin{tabular}{|lccc|}
\hline Variable & aOR & p-value & $95 \% \mathrm{Cl}$ \\
\hline Knowledge & & & \\
\hline Appropriate negative pressure room selection & 1.95 & $0.009 *$ & $1.18-3.22$ \\
\hline COVID-19 symptoms appear to be milder in children than in adults & 0.55 & $0.003^{*}$ & $0.37-0.81$ \\
\hline Education level: postgraduate degree & 1.54 & $0.031^{*}$ & $1.04-2.27$ \\
\hline Age & 0.98 & 0.122 & $0.96-1.01$ \\
\hline $\begin{array}{l}\text { Notes:- *Statistically significant result at the p<0.05 level. Abbreviations: COVID-19, coronavirus } \\
\text { disease 2019; aOR, adjusted odds ratio; } 95 \% \mathrm{Cl}, 95 \% \text { confidence interval; PPE, personal protective } \\
\text { equipment }\end{array}$ & & & \\
\hline
\end{tabular}

\section{Discussion}

This study demonstrated that the prevalence of optimized PPE use was $22 \%$. The prevalences of overusing PPE and underusing PPE were $35 \%$ and $43 \%$, respectively. The low prevalence of optimized PPE use could have been because of several reasons. Firstly, COVID-19 is a an emerging infectious disease that was first isolated and identified in patients who were exposed at a seafood market in Wuhan 
City, Hubei Province, China on December 2019 [32], so data on appropriate PPE for this disease is variable. Secondly, there may have been a shortage of supplies for Thai health care facilities of appropriate PPE compared to the demand because the COVID-19 pandemic is spreading rapidly across countries and regions. The WHO estimates that industry must increase manufacturing by $40 \%$ to supply adequate quantities of PPE [33]. Thirdly, lockdown policy for social distancing may have adversely affected PPE training. A previous study in India showed that the majority surgical trainees felt that the COVID-19 lockdown had adversely affected their learning [34].

In the present study, the low proportion of optimized PPE use was associated with knowledge about disease such as the appropriate negative pressure room selection and knowledge of apparently milder symptoms in children than adults because COVID-19 is an emerging infectious disease [32], the mode of transmission mode is variable, and uncertainty in the early phase of the COVID-19 pandemic [2-4]. In the present study, optimized PPE use was associated with HCWs with a postgraduate degree. Similarly, a previous Ugandan study demonstrated that good HCW practice regarding COVID-19 was associated with holding a diploma (aOR 18.4; 95\% $\mathrm{Cl} 1-322.9 ; \mathrm{p}=0.046)$ [35].

Our study has several limitations. Firstly, the study was a retrospective cross-sectional survey, and some data are missing. Secondly, the sample size was small and possibly unrepresentative of the population of HCWs or IPC teams in Thailand.

\section{Conclusion}

In conclusion, the prevalence of optimized PPE use of HCW was $22 \%$. Optimized PPE use was significantly associated with knowledge about appropriate negative pressure room selection, knowledge of apparently milder symptoms in children than adults, and HCW with a postgraduate degree.

\section{Declarations}

\section{Acknowledgements}

Not applicable.

Authors' contributions Conception and design of the study: V.M. and V.T. and S.C. participated in the study design, wrote the protocol, and collected the data. V.M. and U.J. performed the statistical analyses. V.M. wrote this study. V.M. and S.C. and P.P. coordinated, reviewed, and supervised the study. W.M. reviewed the data and revised the text. All authors have read and agreed to the published version of the manuscript.

\section{Funding}

Not applicable.

\section{Availability of data and materials}


The data used during the current study are available from the corresponding author on reasonable request.

\section{Ethics approval and consent to participate}

The study protocol was reviewed and approved by Institutional Review Board of BIDI, Ministry of Public Health, Thailand. The reference approval letter number is S042h/63_ExPD. Informed consent was waived as participant data were de-identified.

\section{Consent for publication}

Not applicable.

\section{Competing interests}

The authors declare that they have no competing interests.

\section{Author details}

${ }^{1}$ Bamrasnaradura Infectious Diseases Institute, Ministry of Public Health, Tiwanon Road, Nonthaburi, 11000, Thailand. Tel: +66 (0) 2590 3408; Fax: +66 (0) 25903411

\section{References}

1. Rothan HA, Byrareddy SN. The epidemiology and pathogenesis of coronavirus disease (COVID-19) outbreak. J Autoimmun. 2020 Feb 26;109:102433

2. Public Health England. COVID-19: infection prevention and control guidance. https://www.gov.uk/government/publications/wuhan-novel-coronavirus-infection-preventionandcontrol/wuhan-novel-coronavirus-wn-cov-infection-prevention-and-controlguidance\#mobilehealthcare-equipment (accessed 25/03/2020).

3. Xu I, Zhang X, Song W, Sun B, Mu J, Dong X, Wang B: Conjunctival polymerase chain reaction-tests of 2019 novel coronavirus in patients in Shenyang, China. medRxiv. 2020, [Published online ahead of print]:10.1101/2020.02.23.20024935

4. Ong SWX, Tan YK, Chia PY, et al.: Air, surface environmental, and personal protective equipment contamination by severe acute respiratory syndrome coronavirus 2 (SARS-CoV-2) from a symptomatic patient. JAMA. 2020, [Published online ahead of print]:10.1001/jama.2020.3227

5. Jung SM, Akhmetzhanov AR, Hayashi K, et al. Real-time estimation of the risk of death from novel coronavirus (COVID-19) infection: inference using exported cases. J Clin Med. 2020;9(2):E523

6. Hellewell J, Abbott S, Gimma A, et al;Centre for the Mathematical Modelling of Infectious Diseases COVID-19 Working Group. Feasibility of controlling COVID-19 outbreaks by isolation of cases and contacts [published correction appears in Lancet Glob Health. 2020. doi:10.1016/S2214109X(20)30083-8]. Lancet Glob Health. 2020;8(4): e488-e496 
7. Mehta NS, Mytton OT, Mullins EWS, Fowler TA, Falconer CL, Murphy OB, Langenberg C, Jayatunga WJP, Eddy DH, Nguyen-Van-Tam JS. What do we know about children? A systematic review. Clin Infect Dis. 2020; May 11 : ciaa556.

8. Regly E. Italian doctors' fatalities reach tragic levels as they fight COVID-19 in overburdened hospitals. The Globe and Mail. 2020;https://www. theglobeandmail.com/world/article-italiandoctors-fatalities-reach-tragiclevels-as-they-fight-covid-1/.

9. Chen Q, Quan B, Li X, Gao G, Zheng W, Zhang J, et al. A report of clinical diagnosis and treatment of nine cases of coronavirus disease 2019. J Med Virol. 2020.

10. Wang D, Hu B, Hu C, Zhu F, Liu X, Zhang J, et al. Clinical Characteristics of 138 Hospitalized Patients With 2019 Novel coronavirus-infected pneumonia in Wuhan, China JAMA 2020.

11. European Centre for Disease Prevention and Control. Novel coronavirus disease 2019 (COVID-19) pandemic: increased transmission in the EU/EEA and the UK-sixth update. Stockholm, Sweden: ECDC; 2020.

12. Zhang Z, Liu S, Xiang M, Li S, Zhao D et al. Protecting healthcare personnel from 2019-nCoV infection risks: lessons and suggestions. Frontiers of Medicine 2020. doi:101007/ s11684-020-0765$x$

13. WHO Director. General's opening remarks at the media briefing on 2019 novel coronavirus, 2020. Available: https://www. who. int/ dg/ speeches/ detail/ who- director- general- s- opening- remarksat- the- media- briefing- on- 2019- novel- coronavirus- 7- february- 2020 [Accessed 23 Mar 2020].

14. Ferioli M, Cisternino $C$, Leo V, Pisani L, Palange $P$ et al. Protecting healthcare workers from SARSCoV-2 infection: practical indications. European Respiratory Review 2020; 29: 200068 doi: 101183/160006170068-2020

15. Public Health England. Guidance. Reducing the risk of transmission of COVID-19 in the hospital setting Updated 7 April 2020. London, UK: PHE; 2020.

16. Centers for Diseases Control and Prevention. Interim U.S. guidance for risk assessment and public health management of healthcare personnel with potential exposure in a healthcare setting to patients with Coronavirus Disease (COVID-19). Atlanta, Georgia, USA: CDC; 2020.

17. Republic of Turkey Ministry of Health. Public health general directorate. COVID-19 (SARS-CoV-2) infection guideline. COVID-19 medical advisory committee study. Ankara, Turkey: Republic of Turkey Ministry of Health; 2020.

18. Seah I, Agrawal R. Can the coronavirus disease 2019 (COVID-19) affect the eyes? a review of coronaviruses and ocular implications in humans and animals. Ocular Immunology and Inflammation 2020; 28 (3): 391-395. doi: 101080/0927394820201738501

19. Livingston E, Desai A, Berkwits M. Sourcing Personal Protective Equipment During the COVID-19 Pandemic. https://jamanetwork com/journals/jama/fullarticle/2764031. Accessed April 17, 2020.

20. WHO. Rational use of personal protective equipment for coronavirus disease (COVID-19)Available: https://www.who.int/emergencies/diseases/novel-coronavirus-2019/technical-guidance/infectionprevention-and-control 
21. Cook TM. Personal protective equipment during the coronavirus disease (COVID) 2019 pandemic - a narrative review. Anaesthesia. 2020 Jul;75(7):920-927. doi: 10.1111/anae.15071. Epub 2020 Apr 28

22. WHO guidelines on hand hygiene in health care. Geneva: World Health Organization; 2009 (https://www.who.int/infection-prevention/publications/hand-hygiene-2009/en/), accessed 19 March 2020.

23. World Health Organization. Infection prevention and control during health care when COVID-19 is suspected: interim guidance 19 March 2020. Geneva, Switzerland: WHO; 2020.

24. Centers for Diseases Control and Prevention. Interim Infection Prevention and Control Recommendations for Patients with Suspected or Confirmed Coronavirus Disease 2019 (COVID-19) in Healthcare Settings. Atlanta, Georgia, USA: CDC; 2020.

25. Tan SS, Yan B, Saw S, Lee CK, Chong AT et al. Practical laboratory considerations amidst the COVID19 outbreak: early experience from Singapore. Journal of Clinical Pathology 2020: 01-4. doi: 101136/jclinpath-2020-206563

26. WHO Thailand. Coronavirus disease 2019 (COVID-19) Available: https://www.who.int/docs/defaultsource/searo/thailand/2020-05-04-tha-sitrep-71-covid19-final.pdf?sfvrsn=5766517c_2

27. Wua YC, Chena CS, Chan YJ. The outbreak of COVID-19: An overview. Journal of Chinese Medical Association; 83 (3): 217220. doi: 101097/JCMA0000000000000270

28. Liang T. Handbook of COVID-19 Prevention and Treatment. Hangzhou, China: Zhejiang University School of Medicine; 2020.

29. World Health organization. Q\&A: Considerations for the cleaning and disinfection of environmental surfaces in the context of COVID-19 in non-health care settings https://www.who.int/news-room/q-adetail/q-a-considerations-for-the-cleaning-and-disinfection-of-environmental-surfaces-in-the-contextof-covid-19-in-non-health-care-settings

30. Moolasart V, Manosuthi W, Thienthong V, Vachiraphan A, Judaeng T, Rongrungrueng Y, Vanprapar N , Danchaivijitr S. Prevalence and Risk Factors of Healthcare-Associated Infections in Thailand 2018: A Point-Prevalence Survey. J Med Assoc Thai 2019; 102 (12):1309-16

31. Tan SS, Yan B, Saw S, Lee CK, Chong AT et al. Practical laboratory considerations amidst the COVID19 outbreak: early experience from Singapore. Journal of Clinical Pathology 2020: 01-4. doi: 101136/jclinpath-2020-206563

32. Zhu N, Zhang D, Wang W, Li X, Yang B, Song J, Zhao X, Huang B, Shi W, Lu R, Niu P, Zhan F, Ma X, Wang D, Xu W, Wu G, Gao GF, Tan W, China Novel Coronavirus Investigating and Research Team. A Novel Coronavirus from Patients with Pneumonia in China, 2019.N Engl J Med. 2020 Feb 20; 382(8):727-733.

33. World Health organization. Shortage of personal protective equipment endangering health workers worldwide https://www.who.int/news-room/detail/03-03-2020-shortage-of-personal-protectiveequipment-endangering-health-workers-worldwide

34. Mishra D, Nair AG, Gandhi RA, Gogate PJ, Mathur S, Bhushan P, Srivastav T, Singh H, Sinha BP, Singh MK . The impact of COVID-19 related lockdown on ophthalmology training programs in India - 
Outcomes of a survey. .Indian J Ophthalmol. 2020 Jun;68(6):999-1004. doi:

10.4103/ijo.IJO_1067_20.

35. Olum R, et al. Coronavirus Disease-2019: Knowledge, Attitude, and Practices of Health Care Workers at Makerere University Teaching Hospitals, Uganda. Front Public Health. 2020. PMID: 32426320

Figures

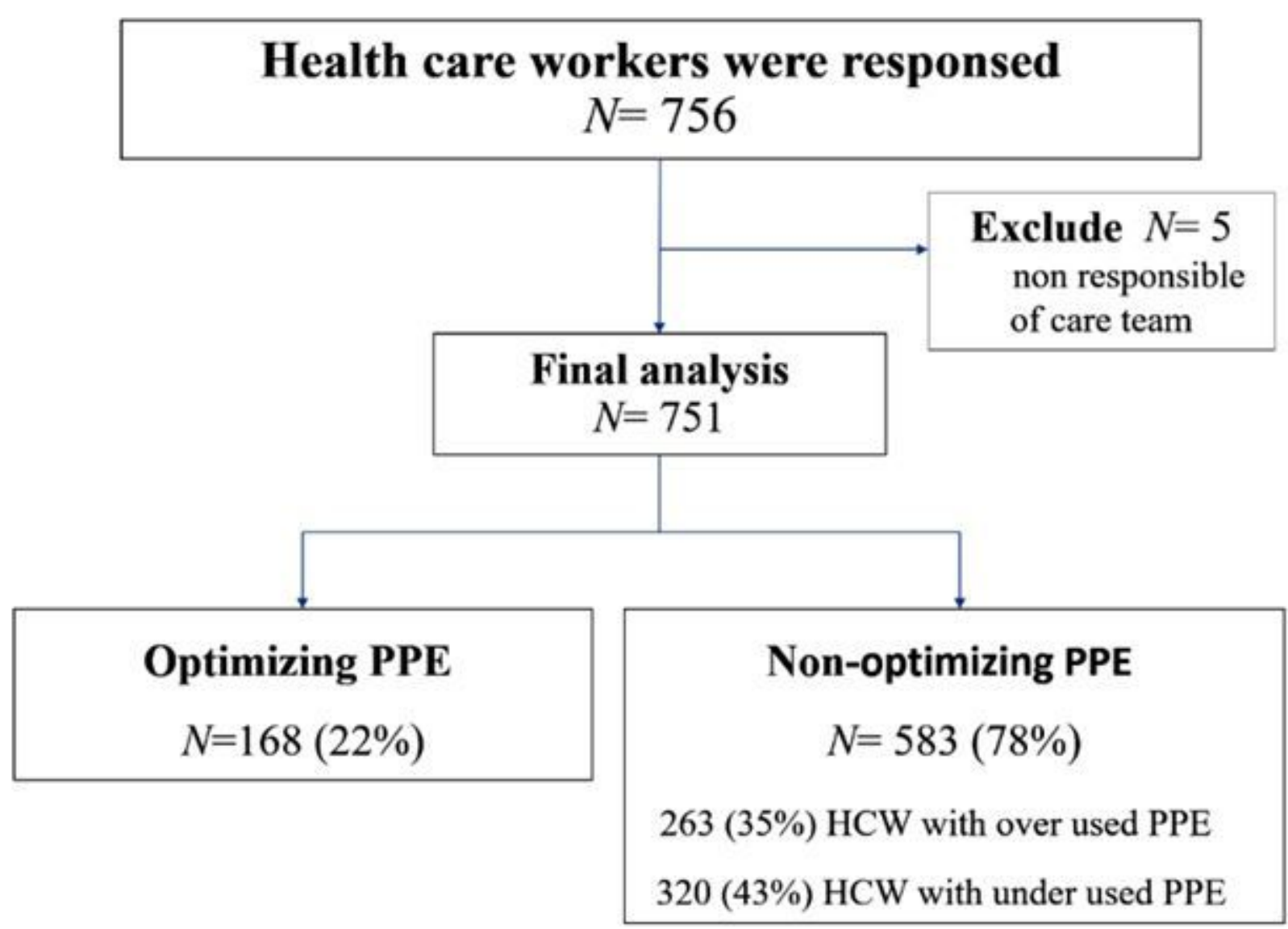

Figure 1

Schematic of study subjects 